\title{
Acceptance of a reusable self-injection device for recombinant human growth hormone: final data from a questionnaire-based, cross-sectional, international, multicenter, observational study in pediatric patients
}

This article was published in the following Dove Press journal:

Medical Devices: Evidence and Research

7 September 2016

Number of times this article has been viewed

\author{
Dirk Schnabel' \\ Carl-Joachim Partsch ${ }^{2}$ \\ Muriel Houang ${ }^{3}$ \\ Sarah Ehtisham ${ }^{4}$ \\ Helen Johnstone ${ }^{5}$ \\ Markus Zabransky ${ }^{6}$ \\ Wieland Kiess ${ }^{7}$ \\ 'Pediatric Endocrinology, Center \\ for Chronic Sick Children, Otto- \\ Heubner-Centrum für Kinder- und \\ Jugendmedizin, Charite, University \\ Medicine, Berlin, Germany; \\ ${ }^{2}$ Endokrinologikum Hamburg, \\ Hamburg, Germany; ${ }^{3}$ Explorations \\ Fonctionnelles Endocriniennes, \\ Hôpital Armand Trousseau, Paris, \\ France; ${ }^{4}$ Mediclinic City Hospital, \\ Dubai Healthcare City, Dubai, United \\ Arab Emirates; ${ }^{5}$ The Newcastle upon \\ Tyne Hospitals NHS Foundation Trust, \\ Newcastle, UK; ${ }^{6}$ Sandoz International \\ $\mathrm{GmbH}$, Holzkirchen, ${ }^{7}$ Department of \\ Women and Child Health, Hospital \\ for Children and Adolescents, \\ University Hospitals, University of \\ Leipzig, Leipzig, Germany
}

Background: A questionnaire-based survey was conducted to assess attitudes toward a reusable self-injection system (SurePal ${ }^{\mathrm{TM}}$ ) among pediatric patients with growth disturbances who were prescribed treatment with Omnitrope ${ }^{\circledR}$ within routine clinical practice.

Methods: This was a multicenter, observational study, incorporated into the noninterventional PAtients TReated with Omnitrope ${ }^{\circledR}$ (PATRO) Children study. Included subjects, or their caregivers, completed a questionnaire on the following five main areas: attractiveness of SurePal ${ }^{\mathrm{TM}}$, training received, using the device, the low drug wastage system, and experience versus other devices used previously (pretreated patients). Responses were based on a 5-point scale, with 2 being the best possible outcome and -2 the worst possible outcome.

Results: In total, 550 patients were included in this study (338 from France, 169 from Germany, and 43 from the UK). The mean age \pm standard deviation of participants was $10.8 \pm 3.5$ years; the majority (57\%) were male and growth hormone treatment naïve (88\%). Almost half (49.8\%) of children prepared their SurePal ${ }^{\mathrm{TM}}$ for injection themselves and $45.5 \%$ performed injections themselves. As patients progressed into their teens, the majority $(\geq 75 \%)$ favored preparing SurePal ${ }^{\mathrm{TM}}$ and performing injections themselves, rather than seeking assistance. The attractiveness of SurePal ${ }^{\mathrm{TM}}$ was rated as excellent/good by $84.7 \%$ of patients overall; this rating was similarly high ( $\geq 79 \%)$ across countries and age-groups. Preparing (88.8\%) and using (83.3\%) SurePal ${ }^{\mathrm{TM}}$ were rated as very easy/easy by most patients; these ratings were similarly high, irrespective of country or age-group. The dose-memory function was rated as very helpful/helpful by $66.2 \%$ of patients. Among 246 patients who reported using the low drug-waste feature, $87.4 \%$ found it helpful. Among pretreated patients $(\mathrm{n}=64), 78.2 \%$ reported that SurePal ${ }^{\mathrm{TM}}$ was much better/ better than their previous device.

Conclusion: These data confirm the ease of use and patient preference for SurePal ${ }^{\mathrm{TM}}$ among pediatric patients with growth disturbances.

Keywords: PATRO children, Omnitrope ${ }^{\circledR}$, SurePal ${ }^{\mathrm{TM}}$, self-injection, growth hormone, intervention adherence

\section{Introduction}

Recombinant human growth hormone $(\mathrm{rhGH})$ is used for the treatment of a variety of growth disorders in childhood/adolescence, which include growth hormone (GH) deficiency, Turner syndrome, short children born small for gestational age, chronic renal
Correspondence: Markus Zabransky Sandoz Biopharmaceuticals, Hexal AG, Industriestr. 25, D-83607, Holzkirchen, Germany

Tel +498024 4762255

Email markus.zabransky@sandoz.com 
insufficiency, and Prader-Willi syndrome. ${ }^{1}$ Adherence to the recommended treatment regimen is important for successful outcomes with rhGH therapy to ensure that patients reach their target height. ${ }^{2,3}$ Poor adherence is associated with reduced clinical effectiveness and a possible increase in health care costs. ${ }^{4}$

Adherence to pediatric rhGH therapy is suboptimal, ${ }^{4-6}$ with up to half of children not fully adherent. ${ }^{3}$ Improving adherence to therapy may be challenging, given the need for long-term subcutaneous administration of rhGH. ${ }^{7}$ Enhanced self-administration devices may play a role in improving adherence., ${ }^{2,3}$ Device-related factors affecting adherence include the patient's preference for the delivery device, its simplicity, convenience, and ease of use, together with the provision of appropriate education and training in the administration technique. ${ }^{3,8}$

$\mathrm{GH}$ injection devices have improved in recent years, with conventional syringes and needles being replaced by more userfriendly devices, designed to better meet patients' needs and preferences. ${ }^{9}$ Factors identified as being important in the design of a $\mathrm{GH}$ injection device intended for long-term use include reliability, ease of use, lack of pain, safety during use/storage, and the number of steps involved in the injection process. ${ }^{10,11}$

SurePal ${ }^{\mathrm{TM}}$ is a reusable self-injection system that has been developed to support daily administration of Omnitrope ${ }^{\circledR}$ (somatropin; Sandoz, Kundl, Austria). SurePal ${ }^{\mathrm{TM}}$ is specifically designed to be easy and convenient to use and to minimize drug wastage. ${ }^{7}$ In a study conducted to validate usability and assess ease of use of SurePal ${ }^{\mathrm{TM}}$ in adults and children/adolescents $(n=106)$ in Germany and the US, 92\% of participants rated the injection procedure (into an injection pad) as very easy or easy. ${ }^{7}$ In addition, $99 \%$ were able to disassemble the pen device successfully. Both naïve and experienced participants found the pen easy to use, which is a factor associated with successful adherence to treatment.

We have previously reported preliminary findings from an observational, questionnaire-based, cross-sectional, multicenter survey conducted to evaluate acceptability of, and preference for, SurePal ${ }^{\mathrm{TM}}$ in pediatric patients who were prescribed treatment with Omnitrope ${ }^{\circledR}$ within routine clinical care. ${ }^{9}$ Here, we report final results from this study, which include data from France, Germany, and the UK.

\section{Methods}

The study methodology has been reported previously. ${ }^{9}$ Briefly, a questionnaire-based, cross-sectional, international, multicenter (sites in France, Germany, and the UK), observational survey study was conducted, which was incorporated into the ongoing noninterventional PAtients TReated with Omnitrope ${ }^{\circledR}$ (PATRO) Children study. ${ }^{12}$ Patients eligible for inclusion into
PATRO Children were infants, children, and adolescents (either sex) who were receiving treatment with Omnitrope ${ }^{\circledR}$ and who had provided written informed consent. All diagnoses were made by investigators. Patients who had been treated with another rhGH product before starting Omnitrope ${ }^{\circledR}$ were also eligible for inclusion. The study was first approved in the UK (by the National Research Ethics Service Committee South Central - Hampshire A), and subsequently approved by all relevant ethics committees in France, Germany and the UK.

The study questionnaire included questions on the following five main topics: attractiveness of the device, training received, using SurePal ${ }^{\mathrm{TM}}$, the low drug-wastage system, and experience compared with other devices used previously (when applicable). Questions were scored on a 5-point scale, with -2 being the worst possible outcome (eg, very hard or very poor) and 2 being the best possible outcome (eg, very easy or excellent). Most questions also included an option to respond "I don't know". Analyses were conducted for the overall study population and by age, country, and pretreatment (with rhGH) status.

\section{Results \\ Study population}

In total, 550 completed questionnaires were included in this study: 338 from France, 169 from Germany, and 43 from the UK, corresponding to response rates of $62 \%, 76 \%$, and $63 \%$, respectively. Forty-six percent of children completed the questionnaire by themselves, and 54\% had help from a family member or another person. Key characteristics of the study participants are shown in Table 1, and their age distribution is shown in Table 2 . The mean age \pm standard deviation of all participants was $10.8 \pm 3.5$ years, and the majority $(57 \%)$ were males. Most participants (88\%) were GH treatment naïve. The largest group by diagnosis were patients with $\mathrm{GH}$ deficiency $(n=234,43 \%)$, followed by children born small for gestational age $(n=208,38 \%)$, and children with Turner syndrome $(n=31,6 \%)$, Prader-Willi syndrome $(n=17,3 \%)$, or chronic renal insufficiency $(n=1,<1 \%)$. These proportions are generally consistent with those for the overall PATRO Children population. At the time of completing the questionnaire, the mean duration of SurePal ${ }^{\mathrm{TM}}$ use was 107.7 days for the overall study population, 107.2 days for $\mathrm{GH}$ treatment-naïve patients, and 64.8 days for pretreated patients.

\section{Preparing SurePal ${ }^{\mathrm{TM}}$ and performing injections}

Almost half (49.8\%) of children prepared their SurePal ${ }^{\mathrm{TM}}$ for injection themselves, while $47.6 \%$ and $1.9 \%$ had a family 
Table I Key characteristics of study participants

\begin{tabular}{|c|c|c|c|}
\hline Characteristic & Naïve $(n=439)$ & Pretreated $(n=64)$ & Total $(\mathrm{N}=550)$ \\
\hline \multicolumn{4}{|l|}{ Country, n (\%) } \\
\hline France & $274(62.4)$ & $19(29.7)$ & $338(6 \mid .5)$ \\
\hline Germany & $127(28.9)$ & $40(62.5)$ & $169(30.7)$ \\
\hline UK & $38(8.7)$ & $5(7.8)$ & $43(7.8)$ \\
\hline \multicolumn{4}{|l|}{ Sex, n (\%) } \\
\hline Male & $249(56.7)$ & $38(59.4)$ & $3 \mid 3(56.9)$ \\
\hline France & $154(35.1)$ & $9(14.1)$ & $189(34.4)$ \\
\hline Germany & $76(17.3)$ & $25(39.1)$ & $101(18.4)$ \\
\hline UK & $19(4.3)$ & $4(6.3)$ & $23(4.2)$ \\
\hline Female & $190(43.3)$ & $26(40.6)$ & $231(42.0)$ \\
\hline France & $120(27.3)$ & $10(15.6)$ & $145(26.4)$ \\
\hline Germany & $5 I(I I .6)$ & $15(23.4)$ & $66(12.0)$ \\
\hline UK & $19(4.3)$ & $\mathrm{I}(\mathrm{I} .6)$ & $20(3.6)$ \\
\hline Mean (SD, range) age, years & $10.5(3.6,0.8-18.1)$ & $12.2(2.9,4.6-17.6)$ & $10.8(3.5,0.8-18.1)$ \\
\hline France & $11.2(3.6,1.4-18.1)$ & $13.0(1.8,8.1-15.9)$ & $11.3(3.5,1.4-18.1)$ \\
\hline Germany & $9.5(3.2,2.6-17.0)$ & $12.0(3.3,4.6-17.6)$ & $10.1(3.4,2.6-17.6)$ \\
\hline UK & $9.1(4.1,0.8-17.3)$ & $10.9(3.6,6.5-13.8)$ & $9.3(4.1,0.8-17.3)$ \\
\hline \multicolumn{4}{|l|}{ Diagnosis, n (\%) } \\
\hline GHD & $202(46.0)$ & $23(35.9)$ & $234(42.5)$ \\
\hline France & $118(26.9)$ & $4(6.3)$ & $|3|(23.8)$ \\
\hline Germany & $72(16.4)$ & $16(25.0)$ & $88(16.0)$ \\
\hline UK & $12(2.7)$ & $3(4.7)$ & $15(2.7)$ \\
\hline SGA & $|7|(39.0)$ & 31 (48.4) & $208(37.8)$ \\
\hline France & 121 (27.6) & II (I7.2) & $138(25.1)$ \\
\hline Germany & $37(8.4)$ & $18(28.1)$ & $55(10.0)$ \\
\hline UK & $13(3.0)$ & $2(3.1)$ & $15(2.7)$ \\
\hline TS & $24(5.5)$ & $5(7.8)$ & $31(5.6)$ \\
\hline France & $9(2.1)$ & $\mathrm{I}(1.6)$ & $12(2.2)$ \\
\hline Germany & II (2.5) & $4(6.3)$ & $15(2.7)$ \\
\hline UK & $4(0.9)$ & $0(0)$ & $4(0.7)$ \\
\hline PWS & $15(3.4)$ & $2(3.1)$ & $17(3.1)$ \\
\hline France & $8(1.8)$ & I (I.6) & $9(1.6)$ \\
\hline Germany & $3(0.7)$ & I (I.6) & $4(0.7)$ \\
\hline UK & $4(0.9)$ & $0(0)$ & $4(0.7)$ \\
\hline CRI & $\mathrm{I}(0.2)$ & $0(0)$ & $I(0.2)$ \\
\hline France & $0(0)$ & $0(0)$ & $0(0)$ \\
\hline Germany & $0(0)$ & $0(0)$ & $0(0)$ \\
\hline UK & $I(0.2)$ & $0(0)$ & $I(0.2)$ \\
\hline Other & $26(5.9)$ & $3(4.7)$ & $29(5.3)$ \\
\hline France & $18(4.1)$ & $2(3.1)$ & $20(3.6)$ \\
\hline Germany & $4(0.9)$ & I (I.6) & $5(0.9)$ \\
\hline UK & $4(0.9)$ & $0(0)$ & $4(0.7)$ \\
\hline Mean (SD) duration of SurePal ${ }^{\mathrm{TM}}$ use, days & $107.2(153.1)$ & $64.8(73.3)$ & $107.7(144.5)$ \\
\hline France & $114.5(151.7)$ & $110.4(108.0)$ & $122.7(145.6)$ \\
\hline Germany & $79.9(87.4)$ & $43.0(31.6)$ & $70.9(78.9)$ \\
\hline UK & $145.0(274.5)$ & $37.3(38.9)$ & $136.3(264.6)$ \\
\hline \multicolumn{4}{|l|}{ Previous rhGH use, $\mathrm{n}(\%)$} \\
\hline Omnitrope ${ }^{\circledR}$ & $\mathrm{N} / \mathrm{A}$ & $3(0.5)$ & $3(0.5)$ \\
\hline Other & $\mathrm{N} / \mathrm{A}$ & $59(10.7)$ & $59(10.7)$ \\
\hline
\end{tabular}

Note: Missing data are not shown.

Abbreviations: CRI, chronic renal insufficiency; GHD, growth hormone deficiency; ISS, idiopathic short stature; N/A, not applicable; PWS, Prader-Willi syndrome; rhGH, recombinant growth hormone; SD, standard deviation; SGA, children born small for gestational age; TS, Turner syndrome.

member and nurse, respectively, to prepare their device (data missing for $0.7 \%$ of all patients). Injections were performed by $45.5 \%$ of children themselves, by a family member in $50.9 \%$ of subjects, and by a nurse in $2.0 \%$ of subjects (data missing for $1.6 \%$ of all patients). As patients progressed into their teens, the majority ( $\geq 75 \%$ ) favored preparing SurePal ${ }^{\mathrm{TM}}$ and performing injections themselves, rather than seeking the assistance of others. 
Table 2 Age distribution of study participants

\begin{tabular}{ll}
\hline Age (years) & $\mathbf{n}(\%)$ \\
\hline All countries $(\mathrm{N}=550)$ & \\
$\leq 6$ & $91(16.5)$ \\
$7-9$ & $125(22.7)$ \\
$10-12$ & $159(28.9)$ \\
$13-15$ & $139(25.3)$ \\
$\geq 16$ & $29(5.3)$ \\
France $(\mathrm{n}=338)$ & \\
$\leq 6$ & $44(13.0)$ \\
$7-9$ & $59(17.5)$ \\
$10-12$ & $110(32.5)$ \\
$13-15$ & $103(30.5)$ \\
$\geq 16$ & $18(5.3)$ \\
Germany $(\mathrm{n}=169)$ & \\
$\leq 6$ & $33(19.5)$ \\
$7-9$ & $56(33.1)$ \\
$10-12$ & $39(23.1)$ \\
$13-15$ & $31(18.3)$ \\
$\geq 16$ & $7(4.1)$ \\
UK $(\mathrm{n}=43)$ & \\
$\leq 6$ & $14(32.6)$ \\
$7-9$ & $10(23.3)$ \\
$10-12$ & $10(23.3)$ \\
$13-15$ & $5(11.6)$ \\
$\geq 16$ & $4(9.3)$ \\
\hline Note:Missing &
\end{tabular}

Note: Missing data are not shown.

\section{Training}

Overall, most participants were trained in the use of SurePal ${ }^{\mathrm{TM}}$ by a hospital nurse (40.5\%) or their doctor/doctor's assistant (28.4\%). Hospital nurses in France and doctors/doctors' assistants in Germany were the main providers of SurePal ${ }^{\mathrm{TM}}$ training in these countries $(47.6 \%$ and $45.5 \%$ of cases, respectively). In the UK, home care nurses were responsible for SurePal ${ }^{\mathrm{TM}}$ training in the majority of cases (53.5\%), supported by hospital nurses (39.5\%; data missing for $0.4 \%$ of all patients; Figure 1). Across all countries and age-groups, most participants $\left(\geq 75 \%\right.$ ) found that learning to use SurePal ${ }^{\mathrm{TM}}$ was very easy or easy; this proportion was higher $(92.2 \%)$ in pretreated patients than in treatment-naïve patients $(77.7 \%$; data missing for $0.4 \%$ of all patients; Figure 2 ).

\section{Attractiveness and use of SurePal ${ }^{\mathrm{TM}}$}

The attractiveness of SurePal ${ }^{\mathrm{TM}}$ was rated as excellent or good by $84.7 \%$ of responders ( $82.9 \%$ among treatment-naïve patients and $90.7 \%$ among pretreated patients). Across countries and age-groups, at least $79 \%$ of responders rated the attractiveness of SurePal ${ }^{\mathrm{TM}}$ to be good/excellent (Figure 3). Preparing and using SurePal ${ }^{\mathrm{TM}}$ for injection were rated as very easy or easy by most participants $(88.8 \%$ and $83.3 \%$, respectively, for the overall study group; data missing for $0.5 \%$ of all patients in the latter). These ratings were similarly high irrespective of country or age-group, and the proportions were slightly higher among pretreated versus treatment-naïve patients (Figure 4).

The dose-memory function of SurePal ${ }^{\mathrm{TM}}$ was judged to be very helpful or helpful by $66.2 \%$ of subjects (data missing for $1.8 \%$ of all patients), and $84.1 \%$ thought that taking SurePal ${ }^{\mathrm{TM}}$ apart after an injection was very easy or easy (data missing for $0.9 \%$ of all patients). Of the 246 responders who reported that they had used the low drug-waste feature, $87.4 \%$ found it to be helpful (data missing for $1.6 \%$ of all patients).

\section{Experience compared with previous devices used}

Among pretreated patients $(n=64), 78.2 \%$ reported that SurePal ${ }^{\mathrm{TM}}$ was much better/better than their previous device (data missing for $17.6 \%$ of patients). Among this same group, $61.0 \%$ felt that SurePal ${ }^{\mathrm{TM}}$ made their $\mathrm{GH}$ treatment plan easier to follow versus their previously used device (data missing for $17.5 \%$ of patients).

\section{Discussion}

Adherence to rhGH therapy among children is suboptimal. ${ }^{46}$ Device-related factors known to affect adherence include the

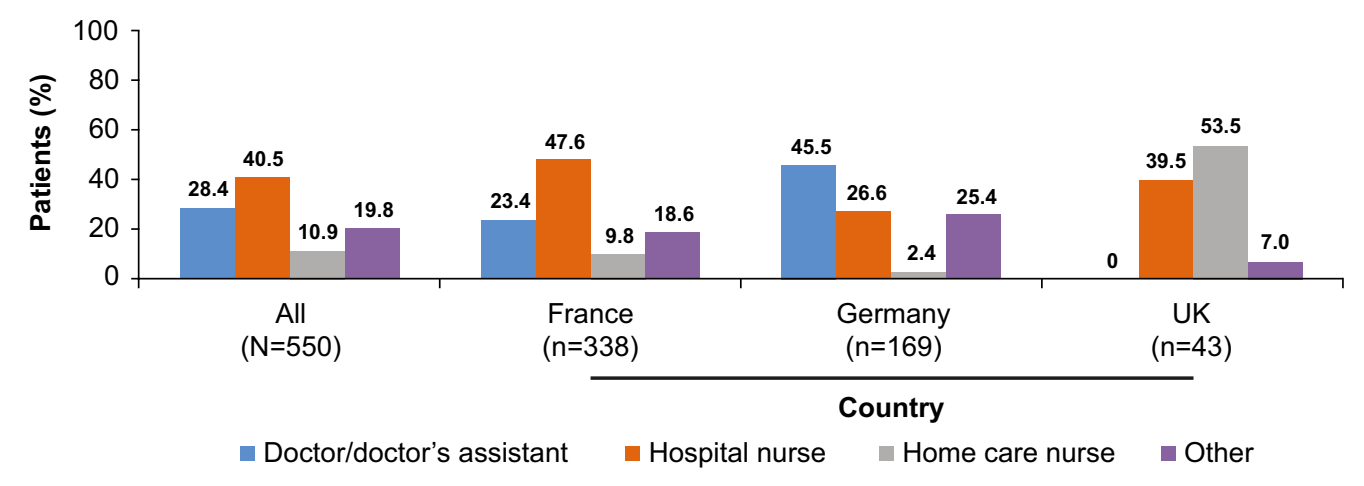

Figure I Source of training in the use of SurePal ${ }^{\mathrm{TM}}$, stratified by country. 

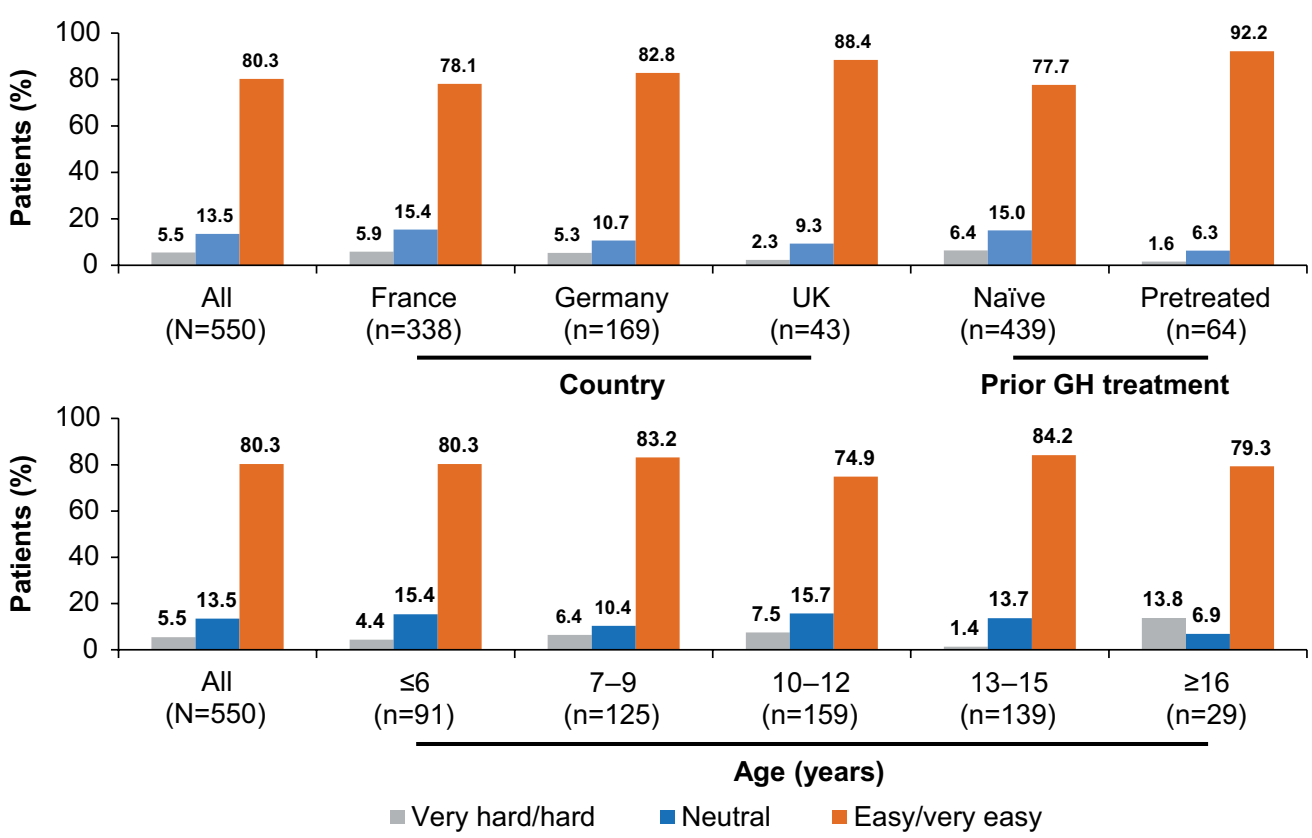

Figure 2 Ease of learning to use SurePal ${ }^{\mathrm{TM}}$, stratified by country, prior $\mathrm{GH}$ treatment, and age.

Note: Responses of "I don't know" ( $0.7 \%$ of all patients) are not shown.

Abbreviation: $\mathrm{GH}$, growth hormone.
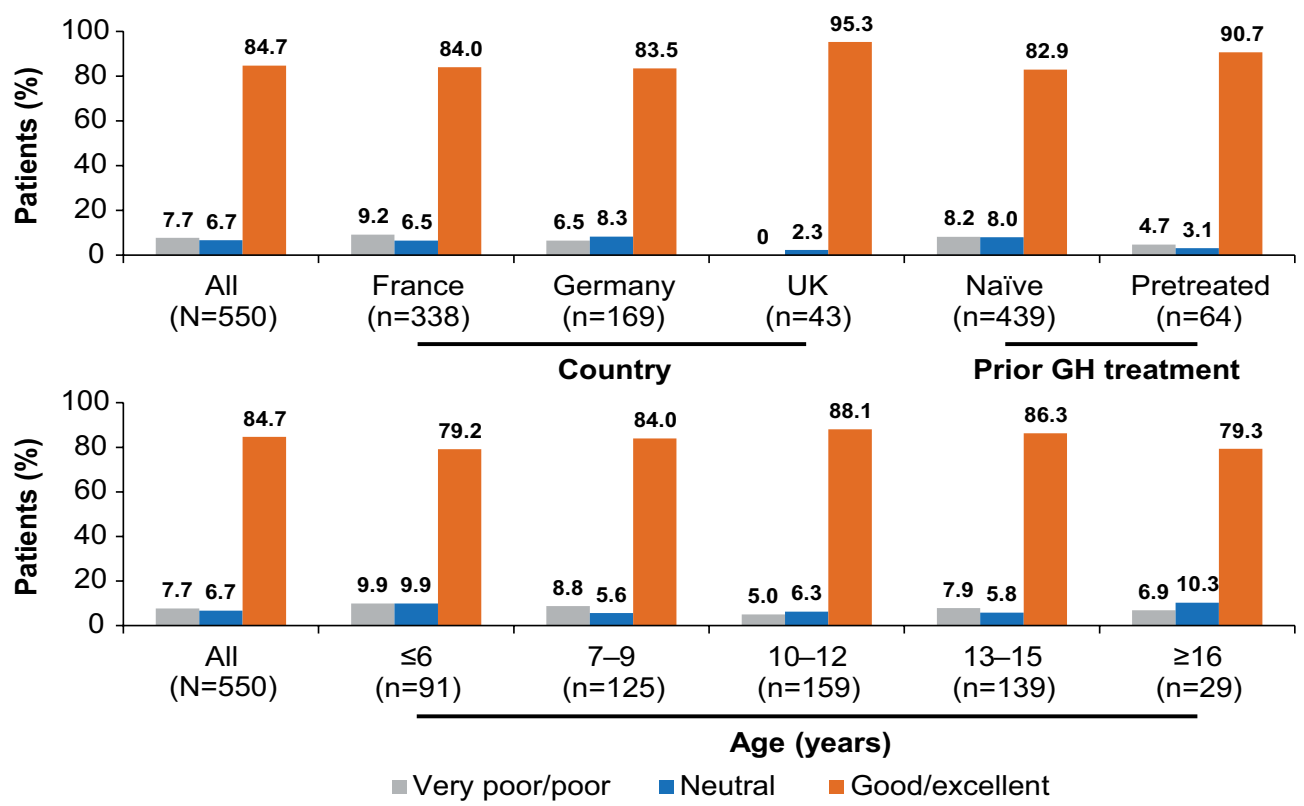

Figure 3 Attractiveness of SurePal ${ }^{\mathrm{TM}}$, stratified by country, prior GH treatment, and age.

Note: Responses of “I don't know” ( $0.9 \%$ of all patients) are not shown.

Abbreviation: $\mathrm{GH}$, growth hormone.

patient's preference for the delivery device, its simplicity, convenience, and ease of use, together with the provision of appropriate education and training in the administration technique. ${ }^{3,8} \mathrm{SurePal}^{\mathrm{TM}}$ is a reusable self-injection system that has been developed to support daily administration of Omnitrope ${ }^{\circledR}$. In the present study, participants overall had a good impression of the device, with $85 \%$ rating its attractiveness as excellent/good. The UK had the highest proportion of subjects who rated the attractiveness as excellent/good. This may be because UK patients are given a choice of different products/ devices when starting treatment and so may have been more aware of alternative devices and had already chosen SurePal ${ }^{\mathrm{TM}}$. More patients in the pretreated group than in the naïve group rated the attractiveness as excellent/good. Again, this may be explained by the fact that pretreated patients were better able to compare SurePal ${ }^{\mathrm{TM}}$ with alternative devices. 
A
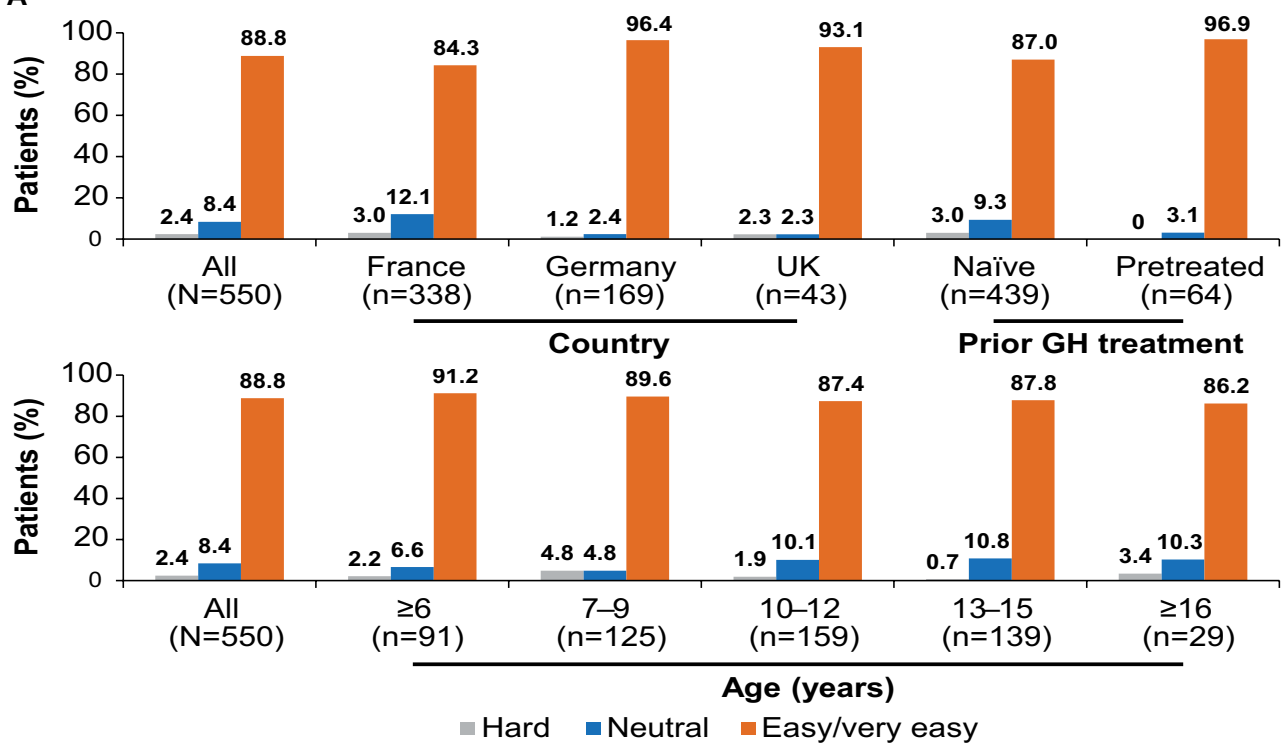

B
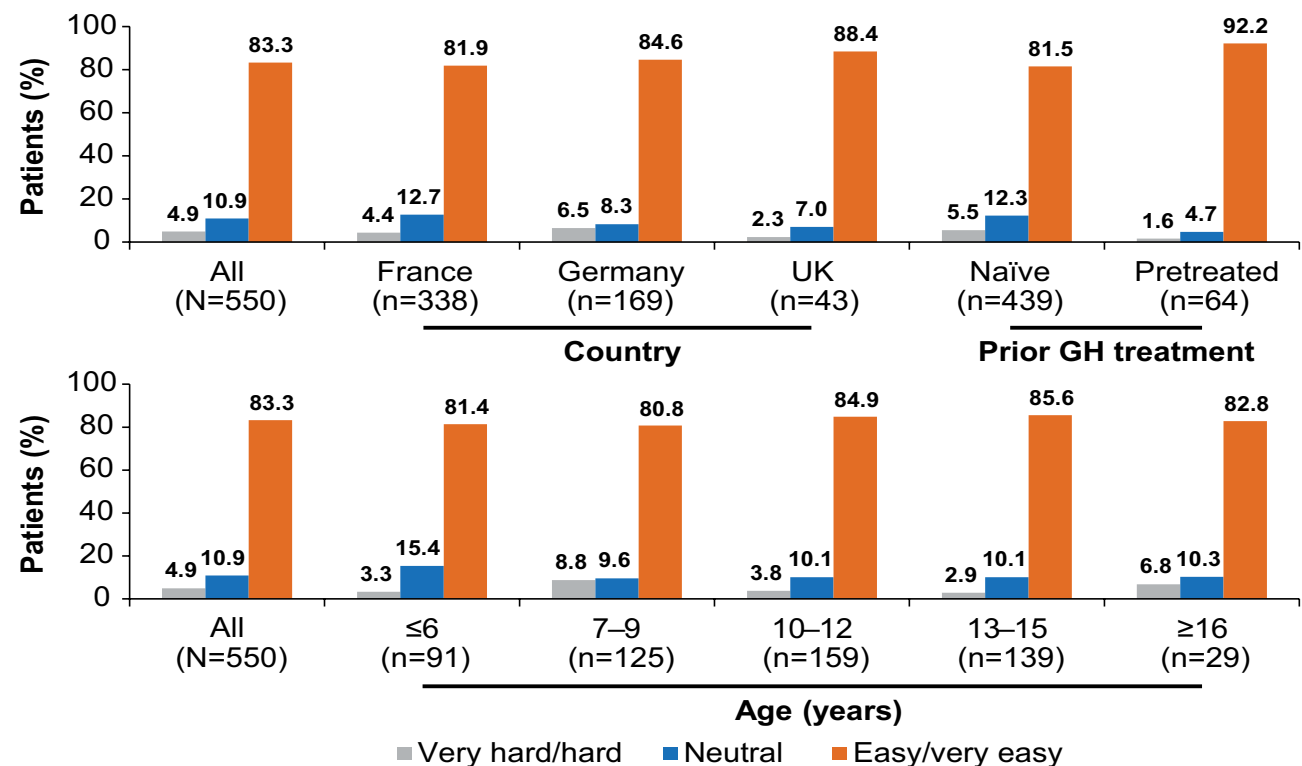

Figure 4 Ease of preparing (A) and using (B) SurePal ${ }^{\mathrm{TM}}$ for injection, stratified by country, prior GH treatment, and age. Note: Responses of “I don't know" ( $0.4 \%$ of all patients) are not shown. Abbreviation: $\mathrm{GH}$, growth hormone.

The vast majority of participants overall found SurePal ${ }^{\mathrm{TM}}$ very easy or easy to use for injection, which is a factor associated with choice of device and successful adherence with treatment. ${ }^{7,11}$ SurePal ${ }^{\mathrm{TM}}$ has various features that may have contributed to patients rating of the device as easy to use. These include an autopriming feature, cartridges that are preassembled and ready to use, a sliding injection button that requires minimum force to perform an injection, and a dose-memory function that enables the correct dose to be preset and locked into the device. ${ }^{7}$
The proportion of participants who responded positively to survey questions was generally slightly higher in the pretreatment group than in the naïve group. This may reflect greater experience among pretreated patients of using a device to administer GH treatment, and their perception of SurePal ${ }^{\mathrm{TM}}$ to be better than their previous device; over threequarters of these patients reported SurePal ${ }^{\mathrm{TM}}$ to be much better/better than their previous device and almost two-thirds felt that SurePal ${ }^{\mathrm{TM}}$ made their treatment plan easier to follow compared with their previous device. 
Overall, $87 \%$ of participants reported that they found the low drug-waste feature helpful. SurePal ${ }^{\mathrm{TM}}$ is specifically designed to minimize drug wastage. If a cartridge in the device does not contain a sufficient amount of drug to inject, the device automatically administers the correct amount of additional drug once a new cartridge is inserted, with no need for priming or adjusting of the dose setting. This feature makes it easier to administer a second injection, compared with some other GH injection devices. ${ }^{7}$ The special features of SurePal ${ }^{\mathrm{TM}}$, such as low drug wastage and dose-memory functions, were more likely to be rated as useful by the youngest age-group (aged $\leq 6$ years). This may be because this group of patients have the least experience of using a device to administer GH treatment, and these features may increase their confidence in using the device correctly for their daily injections. Another possible explanation is that caregivers are more likely to have assisted young children in completing the questionnaire and may be more aware of the value of this function.

Differences were evident between countries in who provided training in the use of SurePal ${ }^{\mathrm{TM}}$. In France, training was most often provided by a hospital nurse, while in Germany and the UK, respectively, a doctor/doctor's assistant and health care nurse fulfilled this role. This may reflect differences in the health care system and how GH treatment is managed and delivered in these countries. Between-country differences were also apparent in the age of profiles of participating children. For example, in the subgroup of participants who were GH treatment naïve, those in France were older (mean age 11.2 years) than in Germany ( 9.5 years) and the UK (9.1 years). Again, this may reflect differences in practice patterns (eg, referral and initiation of GH treatment) for the management of growth disorders.

As expected, younger patients required the most help with preparing and giving injections. However, a greaterthan-expected proportion of the oldest participants also reported needing help, with almost one-quarter of those aged $\geq 13$ years receiving assistance in giving injections from a family member. This may highlight an unmet need for ongoing support throughout childhood and adolescence. It is also possible that caregivers remain involved in the treatment of older children in order to ensure their continued compliance.

The following potential limitations of the study should be highlighted. First, the study was by design open-label and uncontrolled. Second, some subgroup analyses involved relatively small number of patients and therefore should be interpreted with caution. However, the study findings are generally consistent with other data on the usability and ease of use of SurePal ${ }^{\mathrm{TM}} .^{7}$ This earlier study involved participants performing injections into a pad, whereas the present study was based on the use of SurePal ${ }^{\mathrm{TM}}$ in real-world clinical practice.

\section{Conclusion}

The findings from this questionnaire-based, cross-sectional survey in pediatric patients confirm the ease of use and patient preference for the SurePal ${ }^{\mathrm{TM}}$ reusable self-injection system, which was developed to support daily administration of Omnitrope ${ }^{\circledR}$. The use of SurePal ${ }^{\mathrm{TM}}$ may support improved patient adherence to long-term daily administration of $\mathrm{GH}$ treatment.

\section{Acknowledgments}

The authors thank the patients and their caregivers who participated in the study and all participating investigators and their specialist nurses. This study was funded by Sandoz $\mathrm{GmbH}$. Medical writing assistance was provided by Tony Reardon of Spirit Medical Communications Ltd, funded by Sandoz GmbH.

\section{Disclosure}

C-JP is a member of the German PATRO Children board and has received lecture fees from Sandoz/Hexal. DS is a member of the German Omnitrope ${ }^{\circledR}$ advisory board. MH, $\mathrm{SE}$, and $\mathrm{HJ}$ are investigators in the PATRO Children study. WK is an advisor to Sandoz, Ipsen, and Novo Nordisk. MZ is an employee of Sandoz/Hexal AG. The authors report no other conflicts of interest in this work.

\section{References}

1. Pfaffle R. Hormone replacement therapy in children: the use of growth hormone and IGF-I. Best Pract Res Clin Endocrinol Metab. 2015;29(3):339-352.

2. Haynes RB, Ackloo E, Sahota N, McDonald HP, Yao X. Interventions for enhancing medication adherence. Cochrane Database Syst Rev. 2008;(2):CD000011.

3. Kappelgaard AM, Laursen T. The benefits of growth hormone therapy in patients with Turner syndrome, Noonan syndrome and children born small for gestational age. Growth Horm IGF Res. 2011;21(6):305-313.

4. Fisher BG, Acerini CL. Understanding the growth hormone therapy adherence paradigm: a systematic review. Horm Res Paediatr. 2013;79(4):189-196.

5. Aydin BK, Aycan Z, Siklar Z, et al. Adherence to growth hormone therapy: results of a multicenter study. Endocr Pract. 2014;20(1):46-51.

6. De Pedro S, Murillo M, Salinas I, et al. Variability in adherence to rhGH treatment: socioeconomic causes and effect on children's growth. Growth Horm IGF Res. 2016;26:32-35.

7. Rapaport R, Saenger P, Schmidt H, et al. Validation and ease of use of a new pen device for self-administration of recombinant human growth hormone: results from a two-center usability study. Med Devices (Auckl). 2013;6:141-146. 
8. Bhosle M, Klingman D, Aagren M, Wisniewski T, Lee WC. Human growth hormone treatment: synthesis of literature on product delivery systems and administration practices. J Spec Pediatr Nurs. 2011;16(1):50-63.

9. Partsch CJ, Schnabel D, Ehtisham S, Johnstone HC, Zabransky M, Kiess W. Acceptability of the reusable SurePal ${ }^{\mathrm{TM}}$ self-injection device for Omnitrope $\left({ }^{\circledR}\right)$ among pediatric patients: results from a questionnairebased, cross-sectional, multicenter observational study. Med Devices (Auckl). 2015;8:389-393.
10. Dumas H, Panayiotopoulos P, Parker D, Pongpairochana V. Understanding and meeting the needs of those using growth hormone injection devices. BMC Endocr Disord. 2006;6:5.

11. Wickramasuriya BP, Casey A, Akhtar S, et al. Factors determining patient choice of device for GH therapy. Horm Res. 2006;65(1):18-22.

12. Pfaffle R, Schwab KO, Marginean O, et al. Design of, and first data from, PATRO Children, a multicentre, noninterventional study of the longterm efficacy and safety of Omnitrope( $(\mathbb{B})$ in children requiring growth hormone treatment. Ther Adv Endocrinol Metab. 2013;4(1):3-11.

\section{Publish your work in this journal}

Medical Devices: Evidence and Research is an international, peerreviewed, open access journal that focuses on the evidence, technology, research, and expert opinion supporting the use and application of medical devices in the diagnosis, monitoring, treatment and management of clinical conditions and physiological processes. The identification of novel devices and optimal use of existing devices which will lead to improved clinical outcomes and more effective patient management and safety is a key feature. The manuscript management system is completely online and includes a quick and fair peer-review system. Visit http://www. dovepress.com/testimonials.php to read real quotes from authors.

Submit your manuscript here: https://www.dovepress.com/medical-devices-evidence-and-research-journal 